\title{
Case Report: A 10 Weeks Diversional Therapy as an Adjunct to Managing Chronic Pain Associated with Depression
}

\author{
Obiefuna George Umeaku1 ${ }^{1}$, Ferguson Ayemere Ehimen ${ }^{2}$, Chinenye Opogah ${ }^{1}$ \\ ${ }^{1}$ Department of Physiotherapy, Lily Hospitals Limited, Warri, Delta State, Nigeria \\ ${ }^{2}$ Department of Preventive Health Care and Community Medicine, Lily Hospitals Limited, Benin-City, Edo State, Nigeria \\ Email: georgeumeaku@gmail.com
}

How to cite this paper: Umeaku, O. G., Ehimen, F. A., \& Opogah, C. (2021). Case Report: A 10 Weeks Diversional Therapy as an Adjunct to Managing Chronic Pain Associated with Depression. Open Journal of Depression, 10, 14-27.

https://doi.org/10.4236/ojd.2021.101002

Received: December 7, 2020

Accepted: February 16, 2021

Published: February 19, 2021

Copyright $\odot 2021$ by author(s) and Scientific Research Publishing Inc. This work is licensed under the Creative Commons Attribution International License (CC BY 4.0).

http://creativecommons.org/licenses/by/4.0/

\begin{abstract}
Background: Pain is the most common reason for physician consultation, it can interfere with the quality of life and general functioning. The Global Burden of Disease study (2016) states that pain and pain-related diseases are the leading cause of disability and disease burden globally. Chronic pain over time can affect our mental health and participation in daily activities viz our affecting general well-being. Documented evidence has shown that simple medications are useful in $20 \%$ to $70 \%$ of cases but psychological factors such as social support, hypnotic suggestion, diversions such as excitement, or distraction can significantly affect pain's intensity. For holistic care, diversional therapy can be effective in managing chronic pain, as it is a safe and cheap adjunct in managing chronic conditions. Objective: To explore the effect of diversional therapy as an adjunct in managing chronic pain associated with depression. Methodology: This study involves a case report of two patients been managed as a case of cervical spondylosis with radiculopathy associated with depression. Both patients had diversional therapy as an adjunct to conventional physiotherapy. Activity log and chart were developed to monitor the compliance and pain was monitored using the numeric rating scale. Result: Diversional therapy has shown to be a safe adjunct in managing chronic pain associated with depression. Diversional therapy was successfully used as an intervention in decreasing pains of the patients, improving their functioning and participation in activities of daily living. Conclusion/Recommendation: Diversional therapy was found to be a safe adjunct for managing chronic pain-associated depression and consequently reduced the side effect of prolonged medication use. Therefore, diversional therapy should be explored in managing cervical spondylosis with radiculopathy and depression.
\end{abstract}




\section{Keywords}

Physiotherapy, Diversional Therapy, Chronic Pain, Depression

\section{Introduction}

Pain is a personal experience that demands to be felt, but in general term, it is described as an uncomfortable or unpleasant sensation, which could be a sensory and/or emotional experience associated with actual or potential tissue damage, or describes in terms of such damage (Pestana et al., 2015; Merskey \& Bogduk, 1994). It is a complex, biopsychosocial phenomenon that arises from the interaction of multiple neuroanatomical and neurochemical systems with several cognitive and affective processes (Pestana et al., 2015; Katja et al. 2008; Eric, 2012). It has both a sensory and affective component, as well as a cognitive component reflected in the anticipation of future harm which forms part of the increasing perception associated with pain (Suzanne et al., 2010). Untreated pain can have a profound long-lasting effect on social and physical development and can cause permanent changes in the nervous system that will affect future pain experience and development (Suzanne et al., 2010). Chronic pain is recognised as an important problem in the community but our understanding of the epidemiology of chronic pain remains limited (Alison et al., 1999).

Chronic pain is on the rise, with an estimated $10 \%-20 \%$ of the population reporting chronic or recurrent pain (Sturgeon \& Zautra, 2010). Chronic pain persists for three months or longer, while may not necessarily be maladaptive, but oftentimes leads to physical decline, limited functional ability and emotional distress (Asmundson et al., 1998; Turk \& Rudy, 1987; Physiopedia, 2020). Chronic pain can be defined outside the context of duration as an unexplained, irregular, unique and incredibly independent upon the individuals' personal beliefs and coping strategies and it is this chronic pain that subjects to a large amount of study and psychological management strategies (Asmundson et al., 2014). The impact of chronic pain is enormously costing the United States $\$ 60$ billion per year, the United Kingdom about 5 billion pounds, but lack of reliable statistics on the magnitude and financial impact of chronic pain in developing countries (Asmundson et al., 2014; Mark et al., 2013; Vicki \& Amanda, 1998). Use of opioids to managing chronic pain has been associated with abuse, overdose and opioid crisis (Nabarum et al., 2018; Howard et al., 2011; Richard et al., 2003). Geert et al. (1999) asserted that there is growing evidence to support that pain-related fear is more disabling than pain itself. Mental processes such as feeling and belief towards pain have a direct effect on pain perception and pain threshold (Katja et al., 2008). Evidence has shown that placebo-induced analgesia can contribute to cognitive modulation of pain (Pestana et al., 2015; Katja et al., 2008).

Cervical spondylosis is a common cause of chronic pain, affecting $25 \%$ of 
adults under the age of $40,50 \%$ of adults over the age of 40 and $85 \%$ of adults over the age of 60 (Singh et al., 2014). It is the second most common complaint following low back pain. It is a term used to describe a range of progressive degenerative changes that affect all the components of the cervical spine (Kuo \& Tadi, 2020). It is a natural process of aging associated with neck pain, stiffness and could be accompanied by radicular symptoms in cases of compression of neural structures (Singh et al., 2014; Kuo \& Tadi, 2020; McCormack \& Weinstein, 1996). Seventy percent $(70 \%)$ of women and $95 \%$ of men at the age of 65 and 60 respectively are affected, with the fifth and sixth cervical vertebrae the most affected vertebrae. Pain is the most commonly reported symptoms associated with cervical spondylosis, with chronic pain inevitable as age progress (Singh et al., 2014).

Chronic pain often leads to depression and it has been reported that cervical spondylosis can lead to depression. More than one-third of cervical spondylosis patients had depression and anxiety. Few reports suggest that depression could be a cause of cervical spondylosis (Stoffman et al., 2005; Kelly et al., 2012; Al-Tamimi et al., 2013). In a cohort analysis of Stoffman et al., it was discovered that more than one-third of cervical spondylosis patients had depression and anxiety (Stoffman et al., 2005). Management of pain involves the use of various approaches including medical, pharmacological, physiotherapy and diversional therapy (Kuo \& Tadi, 2020; Rahim \& Stambough, 1992; Heller, 1992; Binder, 2007).

Diversional therapy has been used successfully as an intervention to decrease children's pain and behavioural responses during painful procedures (International Association for the Study of Pain (IASP), 2011). However, diversional therapy protocols differ in various ways, most notably in the attention required by the participant to engage in the distraction. Cognitive and behavioural processes, such as distraction, lamaze, and self-hypnosis, can close the gate to subsequent pain perception by diverting attention away from the painful stimulus and toward focal points (Suzanne et al., 2010).

Diversional therapy is gaining relevance as an important aspect in healthcare; thus, the study is aimed at exploring the analgesic effect of diversional therapy in managing chronic pain associated depression.

\section{Methodology}

Case report involves two patients receiving treatment at the Physiotherapy Department of Lily Hospitals Limited, Warri, Delta State Nigeria. Patients were diagnosed and being managed for depression and cervical spondylosis with radiculopathy. Informed consent was gotten from both patients by signing a consent form before the commencement of physiotherapy. Case study 1 had an initial contact with the neurologist who made a diagnosis of cervical spondylosis and depression before subsequent referral for physiotherapy. Case study 2 had an initial consultation with a General Practitioner a few months earlier on account of 
neck pain before presenting to the physiotherapy department.

Both patients were managed by two physiotherapists, but diversional therapy approach was administered by one physiotherapist who monitors participation and holds a one-on-one session with the patients. Pain rating on each visit using the NRS was done on each visit before the commencement of the physiotherapy session.

The research instruments used for this study include:

- Activity Log: This is a chart containing a list of activities pre-selected by patients. These activities include hobbies, recreational activities and various avenue to socialize.

- Activity Checklist: This was used to measure compliance to activities on the $\log$.

- Numeric rating scale (NRS): Is a 10-point scale used to rate patient's pain.

\section{Description of Instrument}

Activity log: This contains a list of hobbies, recreational activities and other activities of daily living as decided by the patient and expected frequency.

Activity chart: The activity chart was used to measure compliance with the prescribed exercise.

Numeric rating scale: This is a patient perception rating of pain. It is an 11-point scale, a score of 0 to 10 , used to measure pain level on each visit. The NRS is interpreted as:

- 0 means no pain;

- 1 - 3 means mild pain;

- 4 - 6 means moderate pain;

- 7 - 10 means severe pain (Aweke et al., 2020).

\section{Case Presentation}

\section{Case report 1}

A 36 years old woman presented at the physiotherapy department of Lily Hospitals Limited following referral by the neurologist of the neurology department of Lily Hospitals Limited on account of neck pain. Patient had been seeing a neurologist in another hospital and was managed for depression. Patient was placed on citalopram (antidepressant).

Patient presented to the physiotherapy department with the following complaint: vertigo, persistent headaches, neck pain, numbness on both upper limbs and difficulty performing activities of daily living. Patient is an engineer, widowed with a child, does not smoke nor drink. Radiological findings showed a normal brain MRI, no cervical radiography was done. Patient was placed on anti-depressant (citalopram) by a neurologist but refused Pregabalin. Assessment was done to rule out red flag and possible differential diagnosis. Treatment goals for physiotherapy were discussed with patient which were targeted at relieving pain, improving spinal posture, improving functional ability in activities 
of daily living, and prevent permanent injury to neural structures.

Patient was managed using conventional physiotherapy approach for pain relief (see Table 1) but with poor prognosis (see Table 4, Figure 1) and participation in activities of daily living. Patient was re-assessed by the physiotherapists on the $16^{\text {th }}$ session; treatment approach was reviewed to incorporate diversional therapy (see Table 2). An activity log was adapted for the patient. Exercise program was adjusted to incorporate leisure, hobbies and socialisation. A checklist was also developed to ensure compliance. Treatment outcome improved with introduction of divisional therapy with reduction in pain and willingness to perform all activities of daily living. Patient was subsequently discharged. Diversional therapy was incorporated to her treatment which included meditation, socialising with friend, attending parties, and hobbies (go swimming).

Patient had a total of 33 sessions of physiotherapy. With an initial 16 sessions of conventional physiotherapy.

Table 1 . Activity report for case study 1 without diversional therapy.

\begin{tabular}{|c|c|c|c|}
\hline Week & Physiotherapy intervention & Pain rating & Functional Limitation \\
\hline 1 to 2 & $\begin{array}{l}\text { - Exercises: Stretches } \\
\text { - Posture correction and ergonomics } \\
\text { - Modalities: TENS ( } 20 \text { minutes, SD mode, } 75 \mathrm{~Hz}, 270 \\
\mu \mathrm{S}) \text {, Thermotherapy: Infra-red ( } 20 \text { minutes) }\end{array}$ & $\begin{array}{l}\text { Twice a week } \quad 8,8,7,7 \text { on NRS } \\
\text { appointment }\end{array}$ & $\begin{array}{l}\text { - Difficulty sleeping } \\
\text { - Difficulty performing overhead } \\
\text { activities } \\
\text { - } \text { Persistent vertigo } \\
\text { - } \\
\text { Pain related fear towards } \\
\text { performing basic activities of daily } \\
\text { living and recreational activities }\end{array}$ \\
\hline 3 to 6 & $\begin{array}{l}\text { - Exercises: Stretches and strengthening exercises to } \\
\text { cervical muscles } \\
\text { - Posture correction and ergonomics } \\
\text { - Modalities: TENS ( } 20 \text { minutes, SD mode, } 75 \mathrm{~Hz}, 270 \\
\text { MS), Thermotherapy: Infra-red ( } 20 \text { minutes) } \\
\text { - Manual cervical traction } \\
\text { - Mechanical cervical traction with } 10 \% \text { body weight } \\
\text { - Reciprocal pulley } \\
\text { - Non-thrust manipulation }\end{array}$ & $\begin{array}{l}\text { Twice a week } \quad 7,8,7,5,6,6,7,5 \\
\text { appointment Mean Pain on NRS: } 8.5\end{array}$ & \\
\hline 7 to 8 & $\begin{array}{l}\text { - Exercise therapy: stretches and strengthening exercises } \\
\text { - Postural correction and ergonomics } \\
\text { - Modalities: TENS ( } 20 \text { minutes, SD mode, } 75 \mathrm{~Hz}, 270 \\
\text { HS), Thermotherapy: Infra-red ( } 20 \text { minutes) } \\
\text { - Soft tissue mobilization with topical analgesic }\end{array}$ & $\begin{array}{l}\text { Twice a week } \quad 6,5,8,7 \text { on NRS } \\
\text { appointment Mean Pain on NRS: } 6.5\end{array}$ & \\
\hline
\end{tabular}

Table 2. Activity report for case study 1 with diversional therapy.

\begin{tabular}{|c|c|c|c|c|c|}
\hline Week & Physiotherapy intervention & Diversional therapy & Duration & Pain rating & Functional Limitation \\
\hline 1 to 2 & $\begin{array}{l}\text { - Exercises: Stretches } \\
\text { - Posture correction and ergonomics } \\
\text { - Modalities: TENS ( } 20 \text { minutes, SD } \\
\text { mode, } 75 \mathrm{~Hz}, 270 \mu \mathrm{S}), \\
\text { - Thermotherapy: Infra-red } \\
\text { ( } 20 \text { minutes) }\end{array}$ & $\begin{array}{l}\text { - Swimming, attending social } \\
\text { events and church service } \\
\text { - One-on-one discussion } \\
\text { session } \\
* * \text { Worsen symptoms after the } \\
\text { first two participations in } \\
\text { recreational activities }\end{array}$ & $\begin{array}{l}\text { Twice a week } \\
\text { appointment }\end{array}$ & $\begin{array}{c}\text { 7,7, 6,5 on NRS } \\
\text { Mean Pain on } \\
\text { NRS: } 6\end{array}$ & $\begin{array}{l}\text { - Difficulty sleeping } \\
\text { - Difficulty performing } \\
\text { overhead activities }\end{array}$ \\
\hline
\end{tabular}




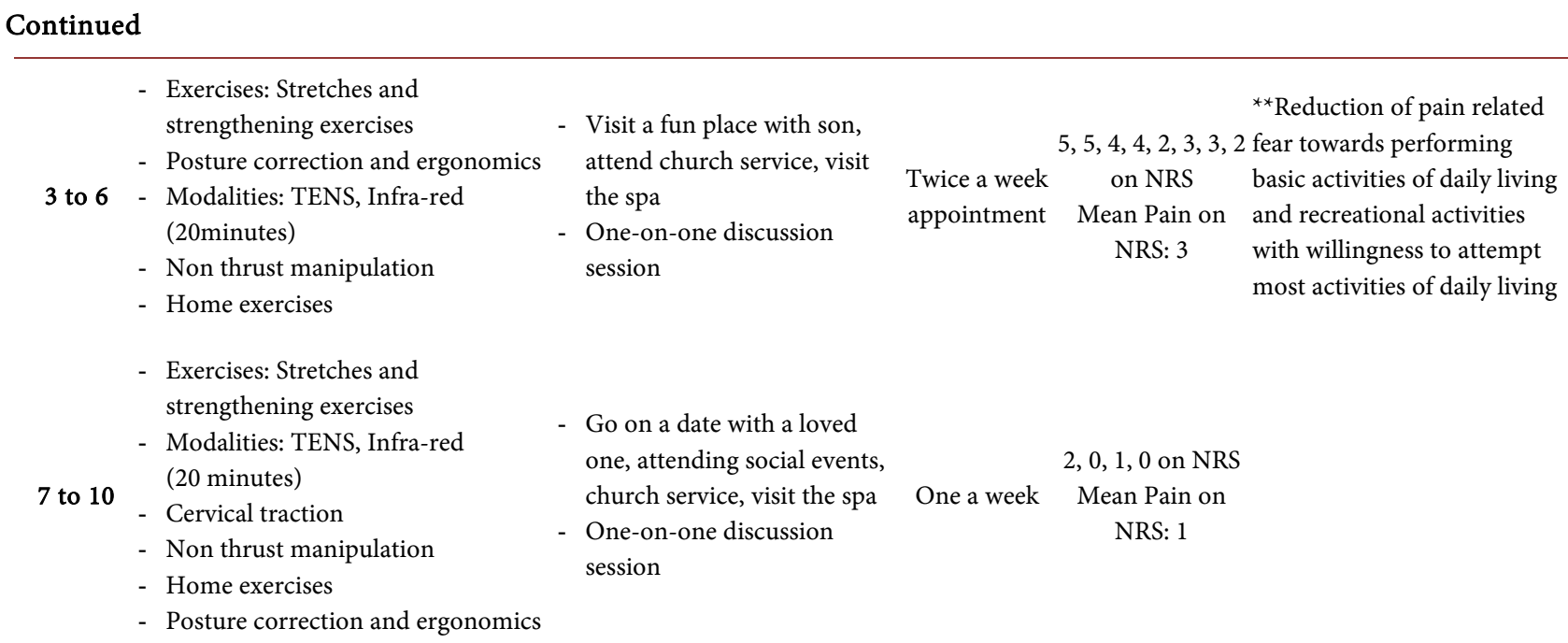

Pain score was taken on each visit prior commencement of physiotherapy. $\mathrm{Pa}$ tient follow up after every session was done via voice call and exercise programs were shared electronically via emails and WhatsApp.

\section{Case report 2}

A case of a 34 years old woman presented at the physiotherapy department of Lily Hospitals Limited on account of neck pain with onset over 8 months ago. The patient discontinued medication for the pain of account of no improvement of symptoms.

The patient presented to the physiotherapy department with the following complaint: vertigo, persistent headaches, neck pain, occasional numbness on both upper limbs and difficulty performing activities of daily living. The patient is businesswoman, married with a child, drinks occasionally but quit smoking.

Physical examination was done to rule out any red flag and possible differential diagnosis. Treatment goals for physiotherapy were discussed with the patient which were targeted at relieving pain, improving spinal posture, improving functional ability in activities of daily living, prevent permanent injury to neural structures and maintaining ideal body weight.

The patient was managed using diversional therapy as an adjunct to conventional physiotherapy approach (see Table 3 ) following an initial consultation. Mean pain rating was found to be: 6 (week 1 - 2), 3 (week 3 - 6), 1 (week 7 - 8). Treatment outcome improved with the use of divisional therapy reduction in pain and willingness to perform all activities of daily living. The patient was subsequently discharged.

\section{Results}

\section{Case study 1 without diversional therapy (PT-0)}

Case study 1 had a total of 16 sessions without diversional therapy. The patient was seen for 8 weeks on twice a week appointment. Results as shown in Table 4 and Figure 1 showed poor outcome. The lowest pain rating was noted on 
Table 3. Activity log for case report 2.

\begin{tabular}{|c|c|c|c|c|c|}
\hline Week & Physiotherapy intervention & Diversional therapy & Duration & Pain rating & Functional Limitation \\
\hline 1 to 2 & $\begin{array}{l}\text { - Exercises: Stretches } \\
\text { - Posture correction and ergonomics } \\
\text { - Modalities: TENS ( } 20 \text { minutes, SD } \\
\text { mode, } 75 \mathrm{~Hz}, 270 \mu \mathrm{S}) \text {, } \\
\text { Thermotherapy: Infra-red } \\
\text { ( } 20 \text { minutes) } \\
\text { - Diversional therapy }\end{array}$ & $\begin{array}{l}\text { - Attend at least a show } \\
\text { - Prepare favourite meal } \\
\text { - Go to the movies } \\
\text { - Counselling/Discussion } \\
\text { session }\end{array}$ & $\begin{array}{l}\text { Twice a week } \\
\text { appointment }\end{array}$ & $\begin{array}{l}\text { 7,6,6,5 on NRS } \\
\text { Mean Pain on } \\
\text { NRS: } 6\end{array}$ & $\begin{array}{l}\text { Difficulty sleeping } \\
\text { Inability to drive } \\
\text { Reduction of pain related } \\
\text { fear towards performing } \\
\text { basic activities of daily living } \\
\text { and recreational activities }\end{array}$ \\
\hline 3 to 5 & $\begin{array}{l}\text { - Exercises: Stretches and strengthening } \\
\text { exercises } \\
\text { - Posture correction and ergonomics } \\
\text { - Modalities: TENS, Infra-red } \\
\text { (20 minutes) } \\
\text { - Non thrust manipulation } \\
\text { - Home exercises }\end{array}$ & $\begin{array}{l}\text { g- Go on a date with a loved } \\
\text { one, attending social } \\
\text { events, church service, visit } \\
\text { the spa } \\
\text { - Counselling/Discussion } \\
\text { session } \\
\text { - Pain coping strategies }\end{array}$ & $\begin{array}{l}\text { Twice a week } \\
\text { appointment }\end{array}$ & $\begin{array}{c}4,3,3,2,3,2 \text { on } \\
\text { NRS } \\
\text { Mean Pain on } \\
\text { NRS: } 2.8\end{array}$ & $\begin{array}{l}\text { Pain occasionally disturbs } \\
\text { sleep }\end{array}$ \\
\hline 6 to 10 & $\begin{array}{l}\text { - Exercises: Stretches and strengthening } \\
\text { exercises } \\
\text { - } \text { Modalities: TENS, Infra-red } \\
\text { (20 minutes) } \\
\text { - Postural correction } \\
\text { - } \text { Home exercises }\end{array}$ & $\begin{array}{l}\text { - Go on a date with a loved } \\
\text { one, attend social events, } \\
\text { church service, Go } \\
\text { swimming with loved one } \\
\text { - Pain coping strategies }\end{array}$ & Once a week & $\begin{array}{l}2,1,1,0,0 \text { on } \\
\text { NRS } \\
\text { Mean Pain on } \\
\text { NRS: } 1\end{array}$ & \\
\hline
\end{tabular}

Table 4. Pain rating for 16 sessions of physiotherapy.

\begin{tabular}{|c|c|c|c|c|c|c|c|c|c|c|c|c|c|c|c|c|}
\hline \multirow{2}{*}{$\begin{array}{c}\text { Week } \\
\text { Session }\end{array}$} & \multicolumn{2}{|c|}{1} & \multicolumn{2}{|c|}{2} & \multicolumn{2}{|c|}{3} & \multicolumn{2}{|c|}{4} & \multicolumn{2}{|c|}{5} & \multicolumn{2}{|c|}{6} & \multicolumn{2}{|c|}{7} & \multicolumn{2}{|c|}{8} \\
\hline & 1 & 2 & 3 & 4 & 5 & 6 & 7 & 8 & 9 & 10 & 11 & 12 & 13 & 14 & 15 & 16 \\
\hline Pain on NRS & 8 & 8 & 7 & 7 & 7 & 8 & 7 & 5 & 6 & 6 & 7 & 5 & 6 & 5 & 8 & 7 \\
\hline Average pain rate: & & 1 & & $\delta+$ & & & & & & +7 & $\frac{107}{16}$ & & & & & \\
\hline
\end{tabular}

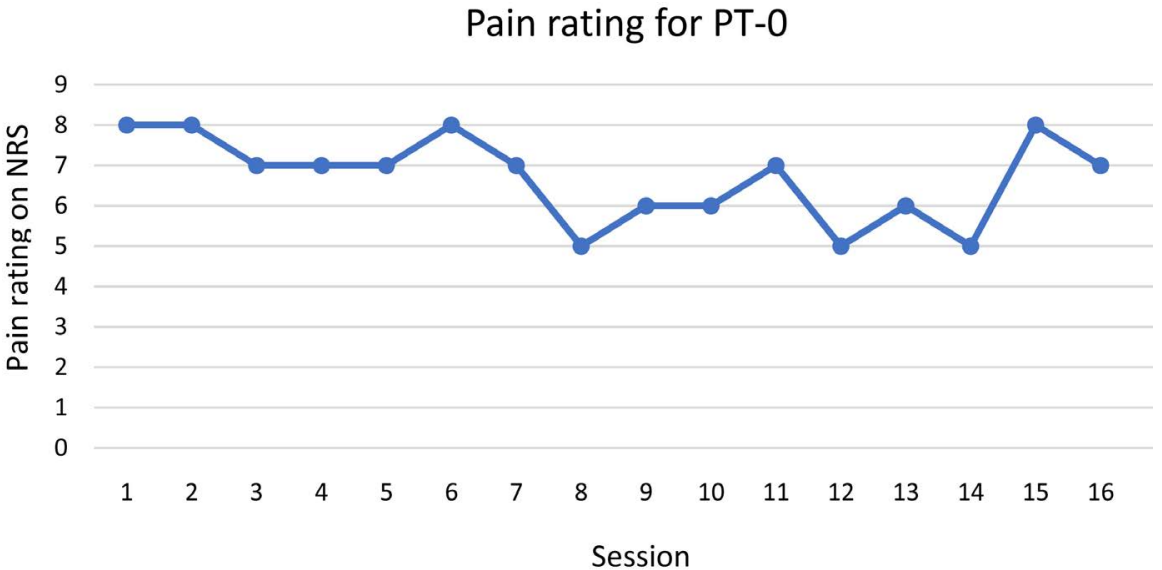

Figure 1. A graphical representation of pain rating for PT-0.

the $8^{\text {th }}$ session, $12^{\text {th }}$ session and $14^{\text {th }}$ sessions. Overall average pain rating following 16 sessions of physiotherapy was 6.7 on a 10-point scale. This value showed that after 16 sessions of physiotherapy, patient's pain persisted with intensity severe. 
The graph above showed the pain rating for 16 sessions of physiotherapy, for 8 weeks (twice a week). It also showed that patient had the highest pain rating of 8 which represents severe pain and the lowest pain rating of 5 which represented moderate pain. Generally, pain rating on most visits fluctuated between 7 and 8 signifying poor outcome.

\section{Activity report for Case study 1 with diversional therapy (PT-1)}

Case study 1 had a total of 16 sessions with diversional therapy. The patient was seen for 10 weeks with twice a week appointment for the first 6 sessions and subsequently once weekly appointment from the $7^{\text {th }}$ to $10^{\text {th }}$ week. The session was reduced to once weekly when the pain was rated 2 on NRS. Results as shown in Table 4 and Figure 1 showed good outcome with diversional therapy. The lowest pain rating was noted on the $14^{\text {th }}$ and $16^{\text {th }}$ session. Overall average pain rating following 16 sessions of physiotherapy was 3.4 on a 10-point scale. This value showed that after 16 sessions of physiotherapy, the patient had mild pain.

Figure 2 showed the pain rating for 17 sessions of physiotherapy, for 8 weeks. It also showed that patient had the highest pain rating of 7 which represents severe pain and the lowest pain rating of 0 which represented no pain. The graph also showed a progressive decline in pain rating with diversional therapy (Table $5)$.

Table 5. Pain rating for 16 sessions of physiotherapy with diversional therapy.

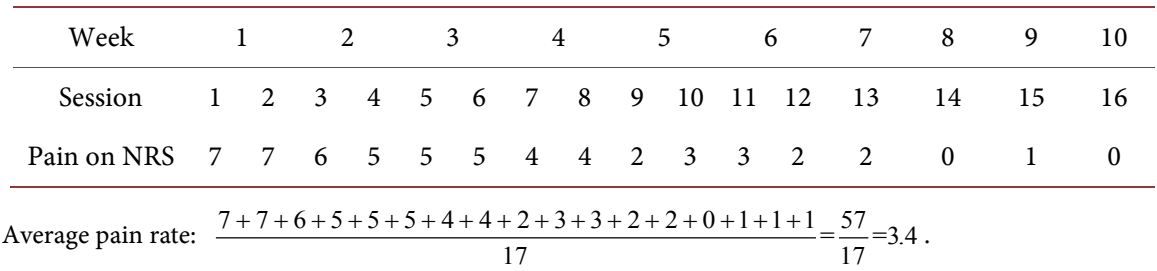

\section{Pain rating for PT-1}

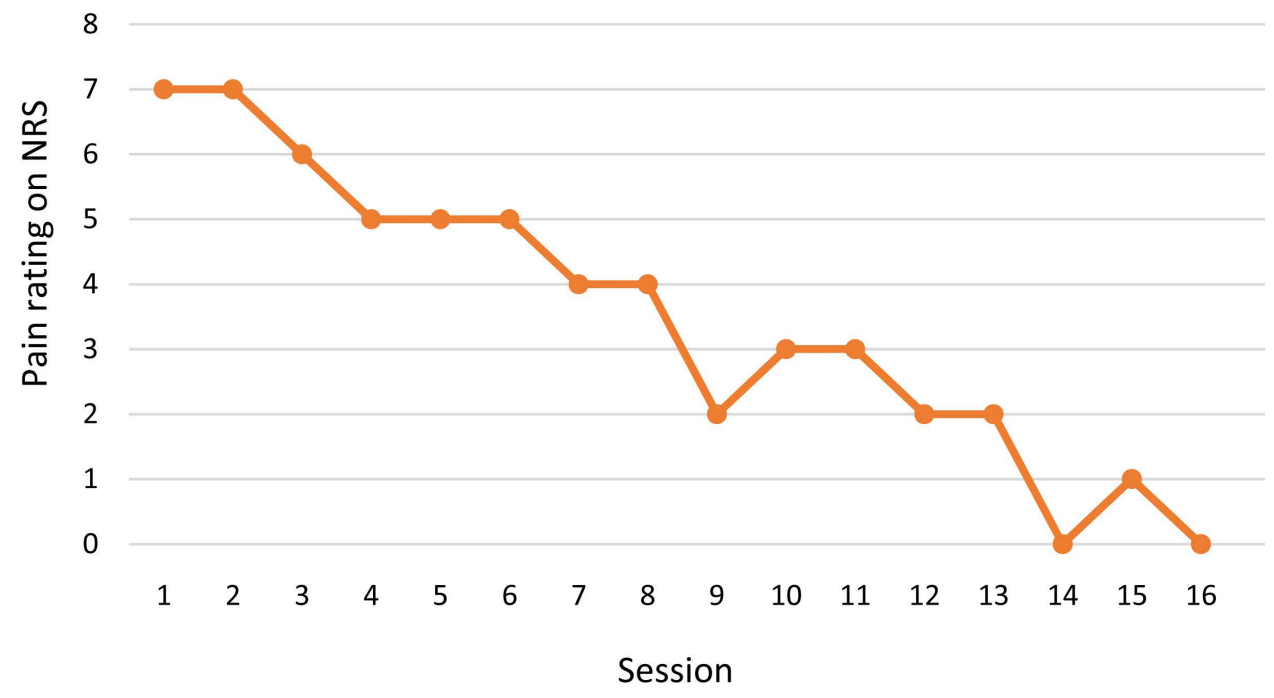

Figure 2. A graphical representation of pain rating for PT-1. 
Activity report for Case study 2 with diversional therapy (PT-2)

Case study 2 had a total of 15 sessions with diversional therapy. The patient was seen for 10 weeks with twice a week appointment for the first 5 sessions and subsequently once weekly appointment from the 7th to 10th week. Results as shown in Table 6 and Figure 3 showed good outcome. The lowest pain rating was noted on the 14th and 15thsession. Overall average pain rating following 15 sessions of physiotherapy was 2.6 on a 10-point scale. This value showed that after 15 sessions of physiotherapy, the patient still had mild pain.

Figure 3 and Table 6 showed the pain rating for 15 sessions of physiotherapy, for 10 weeks. It also showed that patient had the highest pain rating of 7 which represents severe pain and the lowest pain rating of 0 which represented no pain. The graph showed a progressive decline in pain rating with diversional therapy.

Comparing the data from physiotherapy with and without diversional therapy, it can be deduced that, for a better outcome, diversional therapy could be incorporated as an adjunct to managing chronic pain and depression (Figure 4).

\section{Discussion}

The benefit of diversional therapy has been explored in various clinical concept, ranging from oncology, general medicine, paediatrics and acute pain (HansGeorge et al., 2015; Jeffrey et al., 2006; Elizabeth, 2012; Jill \& Lindsey, 2007). This

Table 6. Pain rating for 15 sessions of physiotherapy with diversional therapy.

\begin{tabular}{|c|c|c|c|c|c|c|c|c|c|c|c|c|c|c|c|}
\hline \multirow{2}{*}{$\begin{array}{c}\text { Week } \\
\text { Session }\end{array}$} & \multicolumn{2}{|c|}{1} & \multicolumn{2}{|c|}{2} & \multicolumn{2}{|c|}{3} & \multicolumn{2}{|c|}{4} & \multicolumn{2}{|c|}{5} & \multirow{2}{*}{$\begin{array}{c}6 \\
11\end{array}$} & \multirow{2}{*}{$\begin{array}{c}7 \\
12\end{array}$} & \multirow{2}{*}{$\begin{array}{c}8 \\
13\end{array}$} & \multirow{2}{*}{$\begin{array}{c}9 \\
14\end{array}$} & \multirow{2}{*}{$\begin{array}{l}10 \\
15\end{array}$} \\
\hline & 1 & 2 & 3 & 4 & 5 & 6 & 7 & 8 & 9 & 10 & & & & & \\
\hline Pain on NRS & 7 & 6 & 6 & 5 & 4 & 3 & 3 & 2 & 3 & 2 & 2 & 1 & 1 & 0 & 0 \\
\hline rage pain rate: & & & & & 15 & & & & & & & & & & \\
\hline
\end{tabular}

Pain rating for $\mathrm{PT}-2$

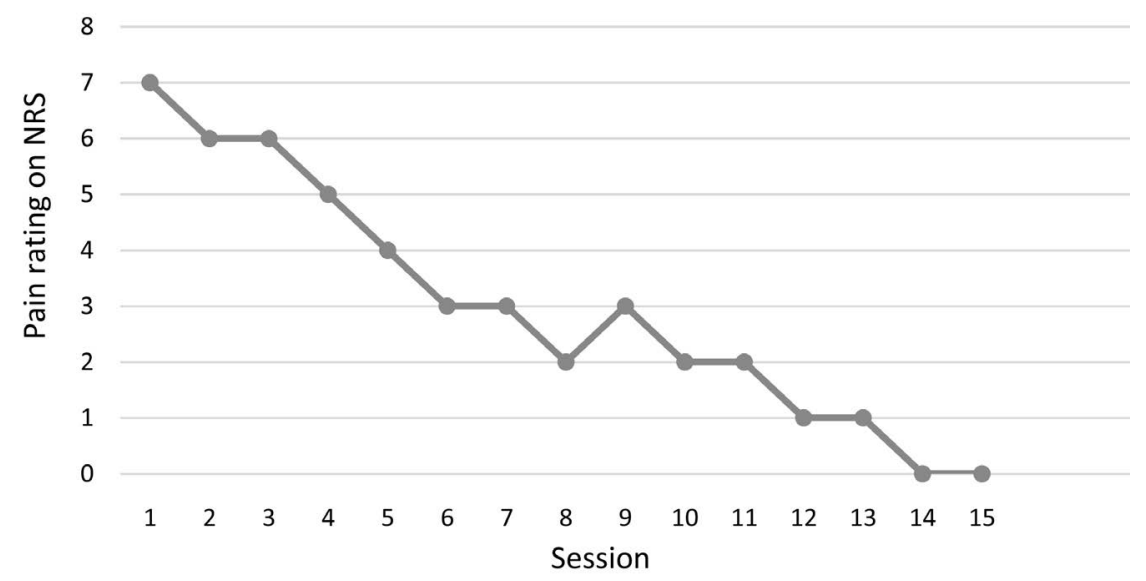

Figure 3. A graphical representation of pain rating for PT-2. 
Graph comparing pain rating between PT-0, PT-1, PT-2

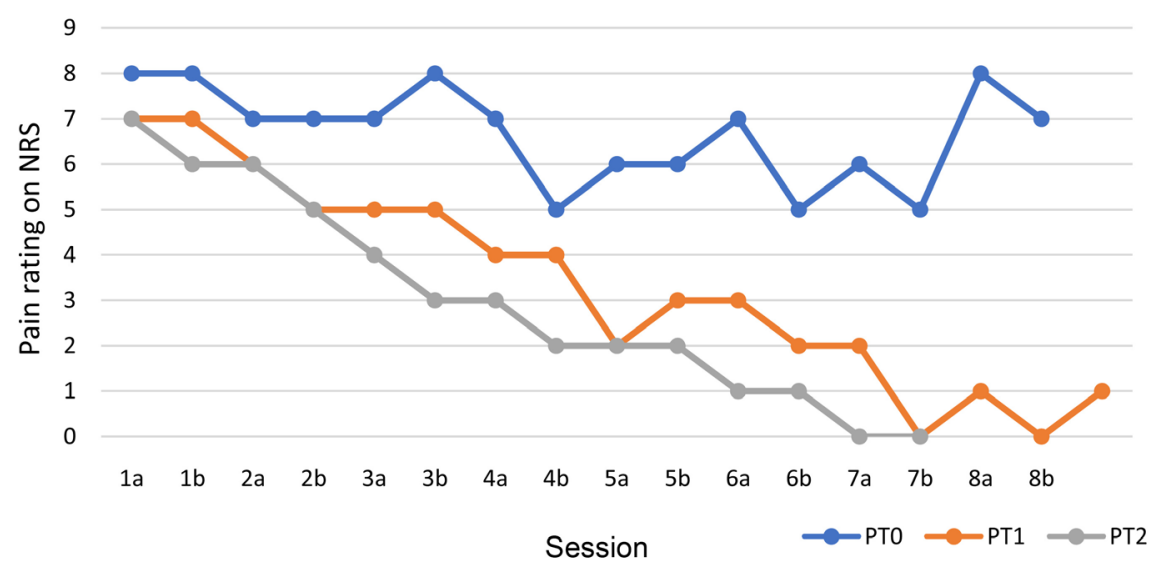

Figure 4. A graph comparing pain rating between PT-0, PT-1, PT-2.

study differs from other studies as various forms of diversion was employed. The choice of diversion was based on the patient's preference.

The case study showed two female patients, managed as a case of depression and chronic pain secondary to cervical spondylosis with radiculopathy. Depression among chronic pain patients is a well-documented fact, thus the need to clinically evaluate chronic pain sufferers for depression. For Chronic pain sufferers, the path back to work or other productive activity can be a long complex one, overcoming both physical and psychological obstacles (Supriya et al., 2017). Patient's in the study were able to overcome both the physical and psychological obstacles they faced as a result of chronic pain using diversional therapy as an adjunct.

Case study 1 was managed initially using conventional physiotherapy interventions, but with poor prognosis. Prognosis improved following the introduction of diversional therapy. Both case studies showed a reduction in symptoms, and improve mental health. Activity log was developed based on the patient's preference, the patient decided hobbies and recreational activities that had been limited by pain. The activities were scheduled for the patient and a checklist to ascertain compliance was developed. Comparing this study with order studies done, diversional therapy has proven to be an effective adjunct in pain management and depression. The outcome of the stated intervention (diversional therapy) is consistent with documented evidence which reinforces the benefits of diversional therapy (Aweke et al., 2020; Nora \& Thomas, 2016).

In another study, distraction among respondents was shown to relieve pain during various procedures ranging from singing, video games, and various forms of play, television visual and auditory stimulation (Jeffrey et al., 2006; Elizabeth, 2012; Jill \& Lindsey, 2007). In children, cartoon-based diversional therapy is effective in managing pain (Nora \& Thomas, 2016; Nabarum et al., 2018). In another study, music therapy, which is a form of diversional therapy was used in managing pain and anxiety levels of cancer patients. The study con- 
cluded that music therapy can reduce cancer pain and anxiety when used along with standard palliative care in cancer patients with moderate to severe pain (Priyadharshini \& Shoba, 2016). According to Huang et al., 2010, music therapy showed a significant reduction in pain experienced by patients when the choice of music determined by the patient (Huang et al., 2010). Comparing this study with Huang et al., 2010, patient choice of diversion for chronic pain sufferers may improve the outcome. Meditation, another form of diversional therapy showed to be effective in decreasing the severity of pain perception and disability in chronic pain patients (Farzaneh et al., 2011; Hassed, 2013).

Generally, from various studies, it can be inferred that diversion/recreation can alleviate distress by helping patients gain relief from their symptoms, but additionally can help patients to develop and to use their strengths and potentials to deal with barriers to health and to facilitate optimal functioning.

\section{Limitation of Study}

The major limitation of the above case study was no objective outcome measure was used to assess depression. This may have shown an objective relationship between pain and depression. Depression was assessed based on patientphysiotherapist interaction during the one-on-one session.

\section{Conclusion}

Managing chronic can be problematic and the need for a safe and more patient-specific approach to managing chronic pain is of utmost importance thus need to explore diversional therapy in managing chronic pain especially one associated with depression. The case reports showed the benefits of diversional therapy in managing chronic pain associated with depression. Diversional therapy has the following benefits: Increasing tolerance and endurance for participation in life and social activities, improving social interaction and skills, enhancing coping skills, maintaining strength, balance and endurance, assisting with community integration after an illness or disabling condition, promoting active aging, wellness, and healthy living.

\section{Recommendation}

Diversional therapy is a safe alternative, with good prognosis. From the case report, we can recommend the use of diversional therapy as an adjunct in managing chronic pain associated with depression.

\section{Conflicts of Interest}

The authors declare no conflicts of interest regarding the publication of this paper.

\section{References}

Alison, M. E., Blair, H. S., Kay, I. P., Cairns, S., \& Alastair, W. C. T. (1999). Epidemiology 
of Chronic Pain in the Community. The Lancet, 354, 1248-1252. https://doi.org/10.1016/S0140-6736(99)03057-3

Al-Tamimi, Y. Z., Guilfoyle, M., Seeley, H., \& Laing, R. J. (2013). Measurement of Long-Term Outcome in Patients with Cervical Spondylotic Myelopathy Treated Surgically. European Spine Journal, 22, 2552-2557. https://doi.org/10.1007/s00586-013-2965-4

Asmundson, G. J. G., Norton, G. R., \& Allerdings, M. D. (1998). Posttraumatic Stress Disorder and Work-Related Injury. Journal of Anxiety Disorder, 12, 57-69. https://doi.org/10.1016/S0887-6185(97)00049-2

Asmundson, G., Gomez-Perez, L., Richter, A., \& Carleton, R. N. (2014). The Psychology of Pain: Models and Targets for Comprehensive Assessment. In Chapter 4 Hubert van Griensven's Pain: A Text Book for Health Care Professionals (pp. 35-48). Amsterdam: Elsevier.

Aweke, Z., Seyoum, F., Shitemaw, T., \& Doba, D. (2020). Comparison of Preemptive Paracetamol, Paracetamol-Diclofenac \& Paracetamol-Tramadol Combination of Postoperative Pain after Elective Abdominal Surgery under General Anesthesia, Ethiopia: A Randomized Control Trial Study. BMC Anesthesiology, 20, Article No. 191. https://doi.org/10.1186/s12871-020-01115-6

Binder, A. I. (2007). Cervical Spondylosis and Neck Pain: Clinical Review. BMJ, 334, 527-531. https://doi.org/10.1136/bmj.39127.608299.80

Elizabeth, C. V. (2012). Effectiveness of Computer Assisted Diversional Therapy on Pain and Behavioural Responses during Veni Puncture Procedures among Preschool Children Attending OPD in Masonic Hospital at Coimbatore. Chennai: The Tamil Nadu Dr.M.G.R. Medical University. http://repository-tnmgrmu.ac.in/id/eprint/3610

Eric, L. D. (2012). Pain Processing in the Human Nervous System: A Selective Review of Nociceptive and Biobehavioural Pathways. Primary Care, 39, 561-571.

https://doi.org/10.1016/j.pop.2012.06.013

Farzaneh, M., Parvaneh, M., Behrooz, D., \& Mohammad, A. A. (2011). The Effect of "Mindfulness Meditation for Pain Management" on the Severity of Perceived Pain and Disability in Patients with Chronic Pain. Salmand Iranian Journal of Ageing, 6. http://salmandj.uswr.ac.ir/article-1-378-en.html

Geert, C., Johannes, W. V., Peter, H. T. G., \& Roeland, L. (1999). Pain-Related Fear Is More Disabling than Pain Itself: Evidence on the Role of Pain-Related Fear in Chronic Back Pain Disability. Pain, 80, 329-339. https://doi.org/10.1016/S0304-3959(98)00229-2

Hans-George, K., Dominic, A., Eli, A., Stefano, C., Beverly, C., Flaminia, C. et al. (2015). A Holistic Approach to Chronic Pain Management That Involves All Stakeholders: Change Is Needed. Current Medical Research and Opinion, 31, 1743-1754. https://doi.org/10.1185/03007995.2015.1072088

Hassed, C. (2013). Mind-Body Therapies: Use in Chronic Pain Management. Australian Family Physician, 42, 112-117.

Heller, J. G. (1992). The Syndromes of Degenerative Spine Disease. Orthopedic Clinics of North America, 23, 381-394.

Howard, G. B., Alan, G. W., Matt, S. B. A., Tracy, W. B. A., Jody, M. C., \& Carl, L. R. (2011). Societal Costs of Prescription Opioid Abuse, Dependence, and Misuse in the United States. Pain Medicine, 12, 657-667. https://doi.org/10.1111/j.1526-4637.2011.01075.x

Huang, S. T., Good, M., \& Zauszniewski, J. A. (2010). The Effectiveness of Music in Relieving Pain in Cancer Patients: A Randomized Controlled Trial. International Journal 
of Nursing Studies, 47, 1354-1362. https://doi.org/10.1016/j.ijnurstu.2010.03.008

International Association for the Study of Pain (IASP) (2011). Classification of Chronic Pain (2nd ed.). https://www.iasp-pain.org/PublicationsNews/Content.aspx?ItemNumber=1673

Jeffrey, L. G. M., Seok, H. K., Alexis, J. K., Michael, H. J., \& Albert, R. (2006). Effectiveness of Virtual Reality for Pediatric Pain Distraction during IV Placement. Cyberpsychology \& Behavior, 9, 207-212. https://doi.org/10.1089/cpb.2006.9.207

Jill, E. M., \& Lindsey, L. C. (2007). Interventions for Paediatric Procedure-Related Pain in Primary Care. Paediatric Child Health, 12, 111-116.

Katja, W., Markus, P., \& Irene, T. (2008). Neurocognitive Aspects of Pain Perception. Trends in Cognitive Sciences, 12, 306-313. https://doi.org/10.1016/j.tics.2008.05.005

Katja, W., Markus, P., \& Irene, T. (2008). Neurocognitive Aspects of Pain Perception. Sciencedirect, 12, 306-313. https://doi.org/10.1016/j.tics.2008.05.005

Kelly, J. C., Groarke, P. J., Butler, J. S., Poynton, A. R., \& O’Bryan, J. M. (2012). The Natural History and Clinical Syndromes of Degenerative Cervical Spondylosis. Advances in Orthopedics, 2012, Article ID: 393642.

https://www.ncbi.nlm.nih.gov/pmc/articles/PMC3227226 https://doi.org/10.1155/2012/393642

Kuo, D. T., \& Tadi, P. (2020). Cervical Spondylosis. Treasure Island, FL: StatPearls Publishing. https://www.ncbi.nlm.nih.gov/books/NBK551557

Mark, I. J., Raga, A. E., \& Osama, A. T. (2013). The Prevalence of Chronic Pain in Developing Countries. Future Medicine, 3, 83-86. https://doi.org/10.2217/pmt.12.83

McCormack, B. M., \& Weinstein, P. R. (1996). Cervical Spondylosis. An Update. Western Journal of Medicine, 165, 43-51.

Merskey, H., \& Bogduk, N. (1994). Classification of Chronic Pain: Descriptions of Chronic Pain Syndromes and Definitions of Pain Terms (2nd ed., p. 210). Seattle, WA: IASP Press.

Nabarum, D., Leo, B. J. D., \& Daniel, C. (2018). Opioid Crisis: No Easy Fix to Its Social and Economic Determinants. American Journal of Public Health, 108, 182-186. https://doi.org/10.2105/AJPH.2017.304187

Nora, D. V., \& Thomas, A. M. (2016). Opioid Abuse in Chronic Pain-Misconceptions and Mitigation Strategies 2016. The New England Journal of Medicine, 374, 1253-1263. https://doi.org/10.1056/NEJMra1507771

Pestana, S. A., Silva, J. R., \& Amilcar, J. T. (2015). Cognitive and Emotional Modulation of Pain. European Psychiatry, 30, 1514. https://doi.org/10.1016/S0924-9338(15)31169-X

Physiopedia (2020). Chronic Pain. https://www.physio-pedia.com/Chronic_Pain

Priyadharshini, K., \& Shoba, N. (2016). Effect of Music Therapy on Pain and Anxiety Levels of Cancer Patients: A Pilot Study. Indian Journal of Palliative Care, 22, 307-311. https://doi.org/10.4103/0973-1075.185042

Rahim, K. A., \& Stambough, J. L. (1992). Radiographic Evaluation of the Degenerative Cervical Spine. Orthopedic Clinics of North America, 23, 395-403.

Richard, I. N., Joel, L. S., Leonard, P. Y., \& Bonnie, G. (2003). Multidisciplinary Treatment of Chronic Pain: Long-Term Follow-Up of Low-Back Pain Patients. Pain, 4, 283-292.

Singh, S., Kumar, D., \& Kumar, S. (2014). Risk Factors in Cervical Spondylosis. Journal of Clinical Orthopaedics and Trauma, 5, 221-226. 
https://doi.org/10.1016/j.jcot.2014.07.007

Stoffman, M. R., Robert, M. S., \& King, J. T. (2005). Cervical Spondylosis and Myelopathy, Depression, and Anxiety: A Cohort Analysis of 89 Patients. Neurosurgery, 57, 307-313. https://doi.org/10.1227/01.NEU.0000166664.19662.43

Sturgeon, J. A., \& Zautra, A. (2010). Resilience: A New Paradigm for Adaptation to Chronic Pain. Current Pain and Headaches Reports, 14, 105-112. https://doi.org/10.1007/s11916-010-0095-9

Supriya, S., Sanjenbam, E. C., \& Atul, C. (2017). Effectiveness of Diversional Activity on Pain and Anxiety during Venipuncture among Children in a Selected Hospital Dehradun, Uttarakhand. Pediatric \& Therapeutics, 7, Article ID: 1000334.

Suzanne, C. S., Brenda, G. B., Janice, L. H., \& Kerry, H. C. (2010). Brunner \& Suddarth's Textbook of Medical and Surgical Nursing (12th ed., pp. 251-256). Philadelphia: Wolters Kluwer Health/Lippincott Williams \& Wilkins.

Turk, D. C., \& Rudy, T. E. (1987). IASP Taxonomy of Chronic Pain Syndromes: Preliminary Assessment of Reliability. Pain, 30, 177-189. https://doi.org/10.1016/0304-3959(87)91073-6

Vicki, R. H., \& Amanda, C. W. (1998). Activities Training: Integrating Behavioral and Cognitive Methods with Physiotherapy in Pain Management. Journal of Occupational Rehabilitation, 8, 47-60. https://doi.org/10.1023/A:1023056515292 